\title{
Festival ManiganSes Com cabeça, tronco e trapos
}

\author{
Rita Martins
}

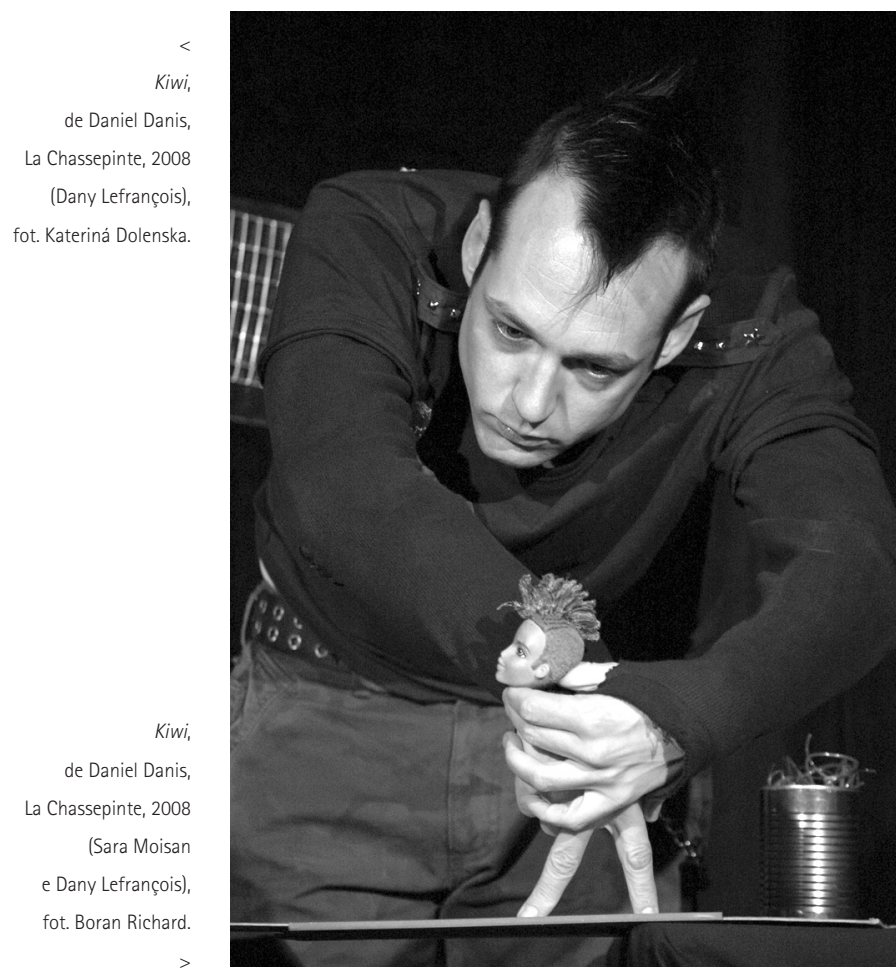

Não se pode dizer que seja fácil assistir ao ManiganSes Festival Internacional das Artes de Marionetas. Atravessase o Atlântico, com destino a Montreal, no Quebeque, que dista $5300 \mathrm{~km}$ de Lisboa. Na cidade francófona, apanhase uma camioneta em direcção ao norte, onde a floresta é tão densa que se torna impossivel distinguir as árvores. Quando algumas manchas de azul começam a rasgar o verde, sabemo-nos na proximidade do Saguenay, o rio que, em 1838, serviu de estrada aos primeiros colonizadores e deu o nome a essa região impenetrável. Finalmente, passadas seis horas, chega-se à tranquila Jonquière, a cidade que recebe, de dois em dois anos, estranhos visitantes.

Apesar do rigor climático e das grandes extensões que cercam as vilas, os saguenenses não vivem orgulhosamente sós. ManiganSes, exemplo de acolhimento e de abertura ao mundo, é uma reunião de amigos provenientes de vários países, um espaço privilegiado de encontro e partilha de uma paixão comum - a marioneta. Na 10. edição do festival, a equipa elegeu o Mediterrâneo e as suas tradições para festejar o vigésimo ano de existência. Artistas de Espanha, Itália, Israel foram os convidados de honra, mas o Canadá também teve uma

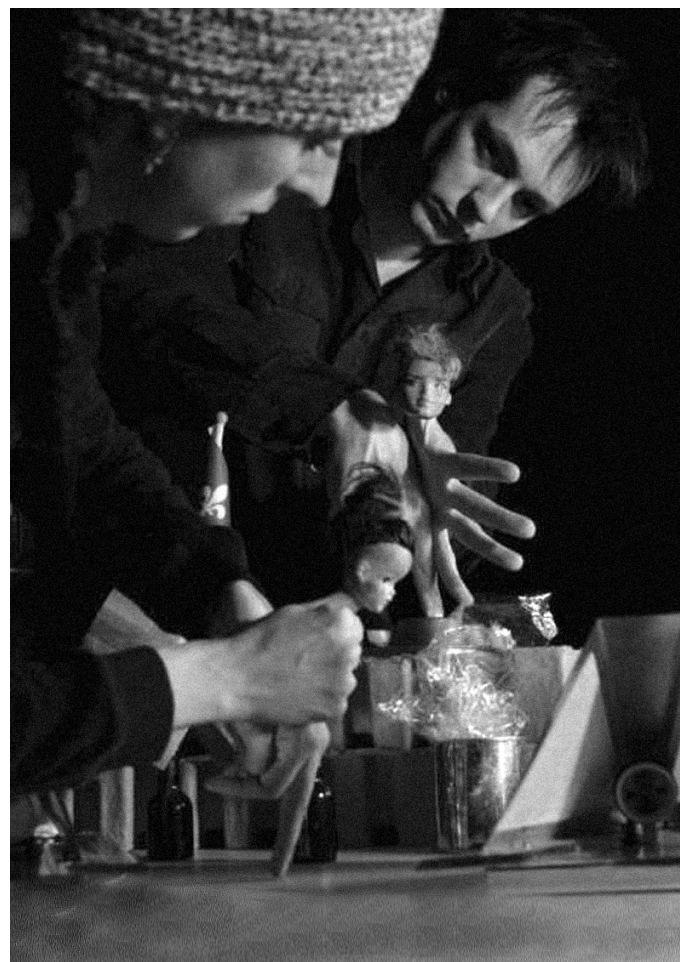

presença muito significativa, tanto pela quantidade como pela qualidade dos espectáculos apresentados.

Se considerarmos o significado da palavra "manigância", cuja origem latina remete para "manus" (mão), podemos verificar como ela é certeira para descrever a actividade do marionetista. Uma "manigância" indica uma manobra secreta e misteriosa, um ardil artificioso. E o que era o bonecreiro, misto de artesão, artista e mago, se não um astucioso inventor de manigâncias? No século $X X$, a tradição ainda mantinha um carácter iniciático e os segredos da arte eram passados de pais para filhos ou transmitidos pelo mestre ao discípulo. Detentor do mistério, o marionetista do teatro popular "desaparecia" atrás do pavilhão, o seu corpo invisivel era criador de ilusões e o seu movimento oculto insuflava vida na matéria inerte. 0 objecto, feito de madeira e pano, ria, cantava, batia, tendo o seu destino manipulado pelo feiticeiro que Ihe havia dado a alma. Mas, enquanto estes feiticeiros estão sujeitos às leis da biologia, a marioneta guarda em si o segredo da eterna juventude. É o caso de Polichinelo, que reapareceu em Jonquière, com os seus cinco séculos de idade e inalterada truculência, pelas mãos de Salvatore Gatto. 0 napolitano apresentou Pulcinella: 500 anni portati bene, 


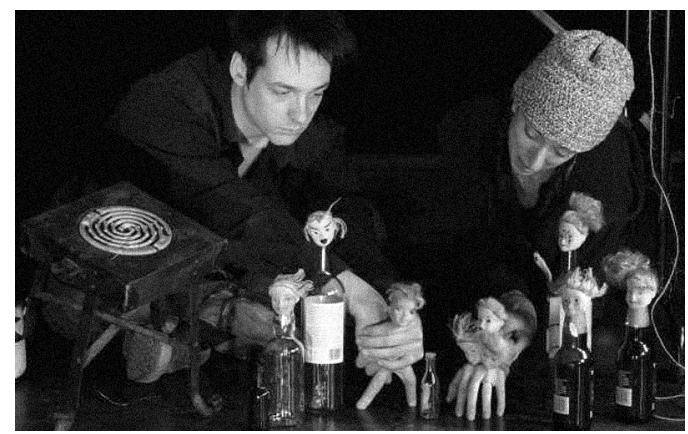

espectáculo acompanhado por um guitarrista e músicas do sul de Itália. 0 ritmo musical foi a principal qualidade desta apresentação, na qual as intensidades da percussão, marcadas pelo som das cabeçadas e bastonadas, podiam atingir tempos rápidos e mesmo aceleradissimos, quando o crescendo de pancadaria atingia o auge. Tais efeitos cómicos, mesmo que produzidos com uma técnica apurada, não compensaram a fraca dramaturgia do espectáculo, apenas desenvolvida em torno do "toca e foge" e do jogo das escondidas. 0 catalão Toni Rumbau, inspirado no teatro popular de Nápoles, também trouxe marionetas de luva e usou a "voz de palheta", chegando a cantar árias de ópera. Em A dos manos (passou por Lisboa, no FIMFA Lx07), as duas ingénuas figuras, de olhos e boca pintados na cara triangular, representaram o conflito entre homem/mulher, vida/morte em cenas satíricas e cruéis. A mais cómica e tenebrosa talvez tenha sido a tourada, seguida do velório do animal e da sua reaparição como espectro. No final, Toni Rumbau convidou a assistência a espreitar o interior do pavilhão, respondeu às questões colocadas e perguntou, um pouco preocupado, às crianças: "Não foi demasiado violento para vocês?" Claro que foi, mas as marionetas têm esta capacidade de criar distanciamento através de uma candura que consente as temáticas mais obscuras.

Nos anos 70, a marioneta, que já tinha sido modelo e instrumento das vanguardas de início do século $X X$ começou a misturar-se com o movimento da performance art, levando ao nascimento de uma tendência mais radical e abstracta chamada "teatro de objectos" (Paska 1991: 5). 0 teatro de marionetas, hoje em dia, aponta para um amplo campo de experimentação, que também inclui as novas tecnologias e pode designar-se, com propriedade, "teatro de formas animadas". 0 corpo do marionetista abandonou, entretanto, a penumbra e passou a integrar o jogo cénico, completando a paisagem onírica que, recorrentemente, é sugerida no universo da marioneta.

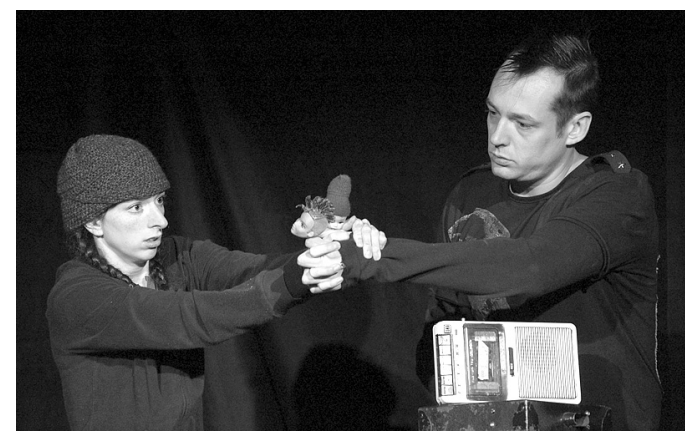

$<>$

Kiwi,

de Daniel Danis, La Chassepinte, 2008 (Dany Lefrançois e Sara Moisan) fot. Kateriná Dolenska.
Para João Paulo Seara Cardoso, quando o segredo da vida das marionetas é revelado ao espectador, a ilusão e o seu mistério não desaparece - "é um mistério muito maior. Porque já não vemos só a vida. Estamos perante a vida em confronto com a morte. A tal existência efémera da marioneta, uma metáfora de nós próprios" (Cardoso 2005: 60).

Durante o festival, houve espectáculos que evidenciaram, de modo muito particular, as capacidades interpretativas dos manipuladores e o fascínio suscitado pelo confronto ente o corpo orgânico e o inorgânico. As israelitas Yael Inbar e Revital Ariely trouxeram a História de Gertrude, uma marioneta com apenas meio corpo, nariz adunco e uma forte personalidade, perceptível pelo notável trabalho de voz de Inbar. A história era simples: quando a aristocrática Gertrude descobriu no corpo da sua manipuladora as pernas que Ihe faltavam, atacou-a e apropriou-se delas para se tornar uma femme fatale. A técnica, porém, exigiu absoluto virtuosismo por parte de Inbar e o efeito foi perturbante. Os seus corpos fundiramse num só, a marioneta derrotou a marionetista, cuja presença vital se dissolveu no objecto, transfigurado em criatura hibrida.

Neste ponto, gostaríamos de fixar, por momentos, a estranheza da relação entre intérprete e objecto sugerida neste trabalho, que dá forma ao paradoxo que é a vida da marioneta. Ao contrário do que seria de esperar, a exposição do corpo do intérprete não anulou a ilusão de autonomia. Este princípio, que tem regido, de modo mais evidente, a técnica de marioneta de fios, persistiu perante os nossos olhos espantados - Gertrude ganhou um corpo inteiro, uma personalidade completa. Porém, a encenação da vitória do objecto manipulado sobre a manipuladora foi mais uma manigância - o espectáculo confirmou, afinal, a exigência do corpo humano. Gertude é o duplo de um corpo falível, vulnerável, mas é este corpo imperfeito e limitado que encerra o segredo da vida e da multiplicidade das formas. 
L'histoire de Gertrude enc. Yael Inbar e Revital Ariely, Yael \& Revital Theatre Group, 2008, fot. Kateriná Dolenska.
0 teatro de marionetas tem vindo a expandir-se como espaço de liberdade técnica e criativa, onde a imaginação pode exercer o seu poder em jogos infindáveis; alguns tão simples que recordam as brincadeiras da infância. 0 espectáculo Kiwi, do colectivo Chassepinte, proveniente do Saguenay, trouxe essas reminiscências, mas a história nada tinha de infantil: na véspera dos jogos olimpicos, as autoridades procedem à limpeza da cidade com a destruição dos bairros degradados. Kiwi e Lichi, dois adolescentes apanhados pelo expurgo, refugiam-se nos subterrâneos da cidade e lutam pela sobrevivência. 0 texto, do escritor canadiano Daniel Danis, desenvolve-se numa sequência de episódios sórdidos e comoventes que falam de um amor ameaçado, da prostituição e do crime, do lado negro de uma cidade em festa.

A encenação deste melodrama suburbano não foi nada menos do que surpreendente. Dany Lefrançois e Sara Moisan, por trás de uma bancada, vendiam os mais variados objectos aos espectadores que entravam na sala. Os cabelos dele espetavam-se num penteado punk e ela usava um gorro azul. Bruscamente, apagaram-se as luzes da sala. Sob o foco de uma lanterna, as duas mesas que serviam de bancada para a "venda de garagem" transformaram-se num palco e os objectos inutilizados no dispositivo cénico, que passou a representar a cidade - desordenada, escura, ameaçadora. Os actores/ personagens desdobraram-se nos seus duplos, manipulando cabeças de bonecos colocadas nas pontas dos dedos. Os corpos dos bonecos, formados pelas mãos dos actores, exibiam uma anatomia mutável e fantástica contradizendo a expressão fixa das caras de plástico. Enquanto a narrativa e os diálogos eram proferidos, ressoando no corpo emotivo dos actores, a manipulação dos objectos era executada com perícia, criando imagens poderosas. A metamorfose dos objectos foi manifestandose neste oscilar permanente entre a dimensão humana, da palavra e do corpo, e a dimensão das coisas, mudas e inertes. Como no faz-de-conta das crianças, assim os objectos se transfiguravam: a cidade era feita de placas de matrícula de automóveis, o jardim era um casaco aveludado, a família dos sem-abrigo eram garrafas com cabeças de bonecos no gargalo.

A fusão entre o actor e o manipulador, aliada à exposição dos procedimentos técnicos, resultou num contraste brutal entre a ingenuidade dos meios e a crueza da narrativa. Recordem-se as cenas em que Kiwi e Lichi, quando se prostituem para comprar a sua "casa de pedra", eram procurados pelo cliente da "máscara do Rato Mickey". Numa das ocasiões, o acto sexual foi ilustrado pelos
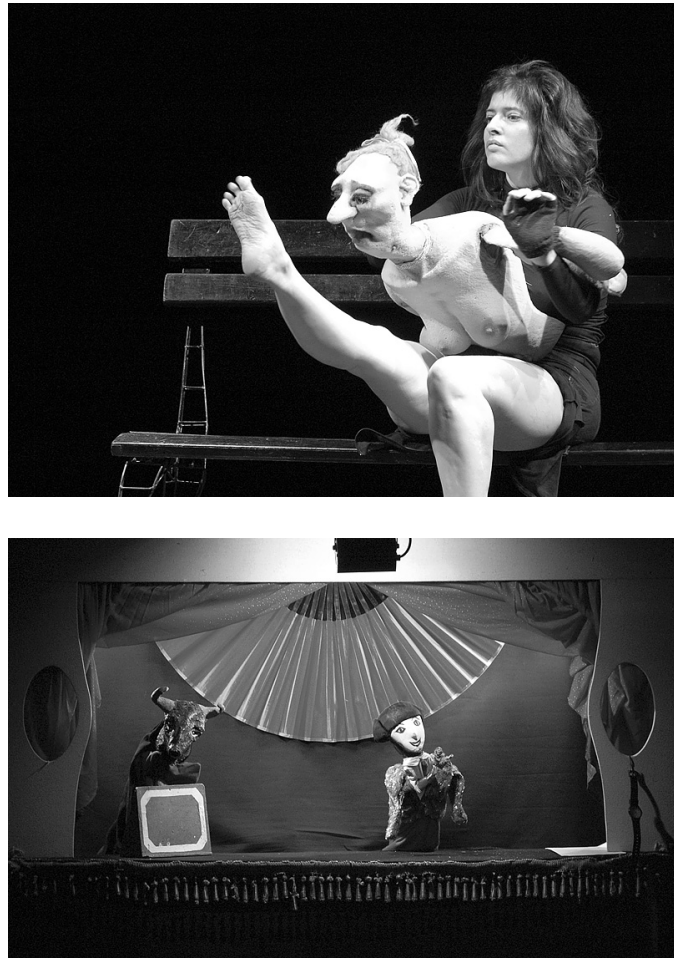

movimentos de um Rato Mickey de peluche, colocado em cima da mão que tinha a cabeça de Kiwi num dos dedos. A simplicidade de recursos não determinou o esvaziamento do drama social, antes amplificou a violência e a carga emotiva. A manigância deste espectáculo residiu pouco nos efeitos sofisticados ou em processos ilusionistas. 0 ardil consistiu numa provocação à imaginação cúmplice do espectador.

Os espectáculos mencionados não esgotaram o interesse de muitos outros apresentados durante o festival, mas evidenciaram tendências estéticas e as possibilidades infindáveis de redefinição das relações entre as marionetas e os marionetistas, o corpo e o objecto, o actor e o seu duplo.

Quando terminou o festival, que decorreu entre $16 \mathrm{e}$ 21 de Setembro, o Outono anunciava-se nas folhas vermelhas das árvores. Para trás ficaram as salas escuras habitadas por criaturas estranhas, o rio tranquilo da cidade e a vastidão do continente a que se chamou Novo Mundo.

\section{Referências bibliográficas}

CARDOSO, João Paulo Seara (2005), "João Paulo Seara Cardoso: Teatro com marionetas", entrevistado por Paulo Eduardo Carvalho e Isabel Alves Costa, Sinais de cena, n. 4, Dezembro, pp. 53-65.

PASKA, Roman (1999), "Avant Propos", Alternatives Théâtrales, n. ${ }^{\circ}$ 65-66: Le théâtre dédoublé, Bruxelles, Institut International de la marionnette. VIEIRA, Luis (2005), "Marioneta, titere, fantoche, roberto, bonifrate, bonecro...", Catálogo de Exposição do Museu da Marioneta de Lisboa, Lisboa, Edição EGEAC. 